\title{
NOTES
}

\section{Graduate Education in Ophthalmology}

Conference at Vancouver, January, 1969

A Conference on Graduate Education in Ophthalmology will be held under the sponsorship of the Royal College of Physicians and Surgeons of Canada and the Canadian Ophthalmological Society at the Bayshore Inn, Vancouver, British Columbia on January 20-22, 1969. All faculties of medicine in Canada which have teaching departments of ophthalmology will participate.

Further information may be obtained from Dr. David A. Rosen, Queen's University, Kingston, Ontario, Canada.

III International Symposium on Ultrasonic Diagnosis in Ophthalmology (Siduo III) AND

International Meeting on Ultrasonic Diagnosis in Medicine

Vienna, June, 1969

Organization: Second Ophthalmological Clinic (Prof. J. Böck), Psychiatric and Neurological Clinic (Prof. H. Hoff), Neurosurgical Clinic (Prof. H. Kraus), Cardiological Clinic (Prof. F. Kaindl), Second Gynaecological Clinic (Prof. H. Husslein), all of the University of Vienna, in co-operation with the Vienna Academy of Medicine.

Topics: Problems of Ultrasonic Diagnosis in Medicine.

Speaking time allowed: papers 10 minutes, communications 6 minutes.

Deadline for submitting scientific contributions: DECEMBER 31, 1968.

Inquiries and registrations: Dr. K. Ossoinig, Wiener Medizinische Akademie, Stadiongasse 6-8, A 1010 Vienna.

The XIIth Annual General Assembly of the Austrian Ophthalmological Society will convene at the same time.

\section{OBITUARY}

\section{ROBERT JAMES BUXTON, 1908-1968}

R. J. Buxton was well known as an ophthalmologist in the south-west of England. Educated at Harrow School, Trinity College, Cambridge, and St. George's Hospital in London, after postgraduate study at St. George's and Moorfields Eye Hospital, he went to India to gain surgical experience, and settled down to practise in Weston-super-Mare in 1937. During the second world war he served in Algeria and Italy and with the army of occupation in Austria. In 1946 he was given hospital appointments in Yeovil and Taunton, from which he resigned in 1961 owing to illness. Buxton's chief interest apart from his profession lay in natural history; he was an expert on flowers and birds and an enthusiastic supporter of the Council for the Preservation of Rural England. 